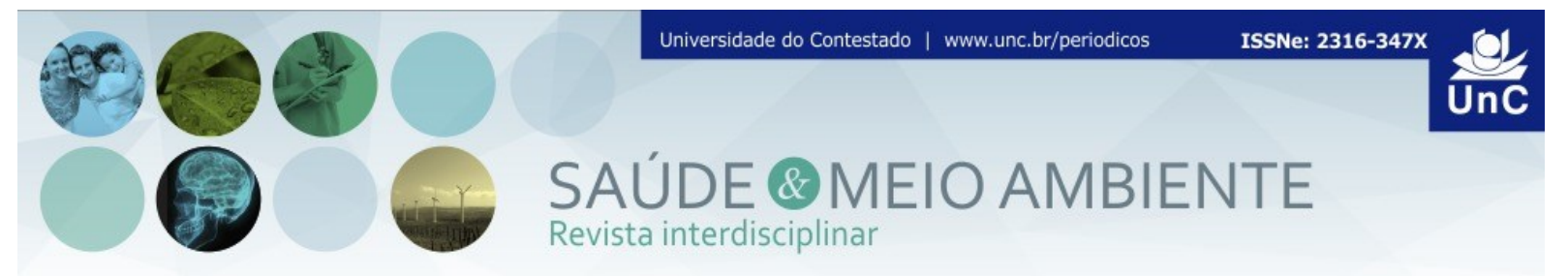

\title{
POLÍTICAS PÚBLICAS DE SAÚDE VISUAL: CONCEPÇÕES E PRÁTICAS NA TRÍPLICE FRONTEIRA ENTRE ARGENTINA, BRASIL E PARAGUAI
}

\author{
Maria Luiza Milani ${ }^{1}$ \\ Damaris Anete Campanini² \\ Luciana Bedin Tadiotto ${ }^{3}$
}

\begin{abstract}
RESUMO
O presente estudo tem como tema as políticas públicas de saúde visual: concepções e práticas na tríplice fronteira entre Argentina, Brasil e Paraguai; como objetivo geral, busca pesquisar a composição das Políticas Públicas de Saúde e as intervenções em saúde visual operacionalizadas na tríplice fronteira entre Argentina, em Puerto Iguazú; Brasil, em Foz do Iguaçu; e Paraguai, em Ciudad Del Este. A metodologia utilizada no desenvolvimento do estudo foi a pesquisa documental, bibliográfica e exploratória em campo, para a coleta de dados com visitas às instituições públicas dos municípios da tríplice fronteira. Realizaram-se entrevistas semi-estruturadas, realizadas com gestores municipais, profissionais de saúde e trabalhadores do sistema público de saúde brasileiro e estrangeiro. De posse destas informações, chegou-se à conclusão de que os três municípios estudados enfrentam dificuldades no setor público de saúde visual, tanto pela falta de profissionais especializados na área da saúde visual, falta de incentivo financeiro e estrutural; com essas dificuldades, a população não tem o atendimento adequado para cuidar da saúde visual.
\end{abstract}

Palavras-Chaves: Política Pública. Saúde visual.

\footnotetext{
${ }^{1}$ Possui graduação em Serviço Social pela Faculdade Espírita do Curitiba (1992), mestrado em Educação pela Universidade Federal de Santa Maria (1999) e doutorado em Serviço Social pela Pontifícia Universidade Católica de São Paulo (2004). Atualmente é professora titular da Universidade do Contestado. Tem experiência na área de Serviço Social, com ênfase em Serviço Social Aplicado; gestão pública. Atua nos seguintes temas: Direitos sociais - políticas públicas e políticas sociais; saúde, assistência social, criança e adolescentes, idoso, jovens, gênero, cultura e desenvolvimento(s). É coordenadora e professora do Programa do Mestrado em Desenvolvimento Regional da UnC. Universidade do Contestado. Santa Catarina. Brasil. E-mail: marialuiza@unc.br

${ }^{2}$ Optometrista. Universidade do Contestado. Santa Catarina. Brasil. E-mail: dadacampanini@hotmail.com

${ }^{3}$ Optometrista. Universidade do Contestado. Santa Catarina. Brasil. E-mail: luciana.bedin@hotmail.com
} 


\title{
PUBLIC POLICIES OF VISUAL HEALTH: CONCEPTIONS AND PRACTICES IN THE TRIPLE BORDER BETWEEN ARGENTINA, BRAZIL AND PARAGUAY
}

\begin{abstract}
The present study has as its theme the public health policies: concepts and practices in the tri-border area between Argentina, Brazil and Paraguay, and as a general goal and search the composition of public health policies and health interventions implemented in the triple border between visual Argentina in Puerto Iguazú, Brazil in Foz do Iguacu and Paraguay in Ciudad Del Este. The methodology used in the development of the study was to documentary research, exploratory, and for data collection with visits to public institutions in the municipalities of the triple frontier, semistructured interviews were conducted with municipal managers, health professionals and workers of the Brazilian public health system and abroad. In possession of this information, it was concluded that the three studied municipal districts face difficulties in public sector visual health, both for lack of specialized professionals in the field of visual health, lack of financial and structural incentive, with these difficulties the population does not have the appropriate service to visual health.
\end{abstract}

Keywords: Public Policies. Visual Health.

\section{INTRODUÇÃO}

O estudo refere-se às políticas públicas de saúde visual: concepções e práticas na tríplice fronteira entre Argentina, Brasil e Paraguai. Ainda, a escolha desse recorte das políticas públicas considera os elementos humanos e peculiares na fronteira trinacional, a fim de se destacar demandas que possam ser contempladas de maneira adequada e eficaz sobre os problemas que, apesar de comuns nesses três países, requerem soluções específicas conforme decisão política de cada um (LINI, 2014).

Na definição de saúde visual segundo a Organização Mundial da Saúde (OMS, 2006) trata-se da capacidade do indivíduo de enxergar binocularmente, com integridade dos meios oculares, ausência de patologia e integridade dos campos visuais. Embora nas últimas duas décadas o Brasil tenha avançado na prevenção e tratamento da saúde visual, as necessidades da população ainda estão sendo atendidas em ritmo aquém do que é adequado ou necessário (PADILHA. 2010).

A situação dos sistemas de saúde em região de fronteira entrou na agenda do debate internacional mais pelas consequências do reordenamento econômico, devido à crise dos anos 1990-2000, e menos pela insatisfação e demanda dos gestores e da população residente na área. Há, entretanto, o reconhecimento do aumento dos fluxos e intercâmbios de pessoas, de serviços e de produtos decorrentes dos processos de integração regional, repercutindo diretamente nos indicadores sanitários e demográficos das cidades fronteiriças, que se tornam corredores econômicos (ARBOLEDA-FLOREZ et al. apud GIOVANELLA, 2004). 
Para a Organização Pan-americana de saúde, o trabalho de saúde pública nas fronteiras significa priorizar e desenvolver ações de saúde e cuidados de saúde nos territórios de fronteira e, especialmente, para gerar recursos, para dar respostas eficientes nas cidades gêmeas. O objetivo de tais ações é reduzir as iniquidades sem saúde, criando autoridades políticas locais à procura de interação e consenso entre redes nacionais de saúde e o desenvolvimento de informação em saúde, garantindo a acesso aos serviços e à qualidade do atendimento, fortalecendo as ações de vigilância epidemiológica e saúde (OPS, 2007).

A partir do exposto, as políticas públicas municipais na área de saúde visual devem estar presentes na agenda nacional e internacional de uma maneira descentralizada, resultando em ações sociais mais dinâmicas pelas experiências concretas que são verificadas nas regiões fronteiriças.

Portanto, o problema do estudo referiu-se às políticas públicas e às intervenções sobre a saúde visual, previstas e praticadas na tríplice fronteira, visando o bem estar da população. O estudo delineou, como objetivo geral, pesquisar a composição das políticas públicas e intervenções em saúde visual operacionalizadas na tríplice fronteira, compostas pelos municípios de Ciudad Del Este-PY, Foz do Iguaçu-BR e Puerto Iguazú-AR.

Assim, a pesquisa desenvolvida justifica-se pela relevância do estudo que aborda, como vem sendo organizados os sistemas de saúde pública nos municípios da tríplice fronteira. A contribuição do estudo visa os esclarecimentos sobre como estão sendo estabelecidos e cumpridos os acordos, propostas e projetos dos diferentes governos. Ainda, a relevância do estudo diz respeito ao processo de cumprimento do direito à saúde do cidadão. O estudo destaca-se, também, pela relevância em reconhecer que os recursos de saúde do modo como estão sendo executados, vem sobrecarregando os médicos que atendem vinculados ao Sistema Único de Saúde (SUS), pela alta demanda dos serviços de saúde visual atendida em Foz do Iguaçu.

O estudo tem como objetivo pesquisar a composição das políticas públicas de saúde e as intervenções em saúde visual operacionalizadas na tríplice fronteira (Argentina-Puerto Iguazú, Brasil-Foz do Iguaçu e Paraguai-Ciudad Del Este).

\section{MATERIAIS E MÉTODOS}

Para o desenvolvimento do estudo elegeu-se a pesquisa bibliográfica exploratória, a qual foi realizada sobre as políticas públicas de saúde visual da tríplice fronteira entre Argentina, Brasil e Paraguai. Para elucidar as problemáticas enfrentadas na oferta da saúde pública na tríplice fronteira, foi realizado levantamento bibliográfico. Também, a pesquisa de campo levou em conta a aceitação: 1) dos gestores municipais, enfermeiros, assistente social e agente comunitário em participar do estudo; 2) funcionários municipais que atuam diariamente com os usuários do SUS residentes na área de fronteira Argentina, Brasil e Paraguai. Para delimitar a 
amostragem, utilizou-se informações do quadro de funcionários municipais que atuavam no setor de atendimento à população dos municípios, o que resultou em uma amostra de 12 pessoas. Os questionários aplicados a esses entrevistados continham perguntas abertas e fechadas para obtenção de conhecimentos acerca dos serviços públicos em saúde visual, relacionados ao acesso de atendimento à população; quanto aos serviços prestados pelos recursos públicos, programas e projetos desenvolvidos para atender a saúde visual.

O estudo de campo envolveu seres humanos e, segundo a resolução 196/96 e 466/2012, ambas do Conselho Nacional de Saúde (CNS), foi aprovado pelo Comitê de Ética em Pesquisa da Universidade do Contestado (UnC), parecer 1.745.527. Todos os participantes da pesquisa, de forma livre e esclarecida, assinaram o Termo de Consentimento. Foram entrevistados:

\begin{tabular}{|l|l|l|l|l|}
\hline MUNICÍPIO & GESTOR & ENFERMEIROS & ASS. SOCIAL & AG. COMUNITARIO \\
\hline Foz do Iguaçu-BR & GMFI 01 & E FI 01 & AS FI 01 & A C FI 01 \\
\hline Ciud Del Este-PY & GMCDE 01 & E CDE 01 & AS CDE 01 & A C CDE 01 \\
\hline Puerto Iguazú-AR & GM PI 01 & E PI 01 & AS PI 01 & A C PI 01 \\
\hline
\end{tabular}

Fonte: Dados da Pesquisa (2016)

Optou-se por não revelar a identidade dos entrevistados, os mesmos serão identificados por siglas: GM FI (Gestor de Municipal de Foz do Iguaçu); GM PI (Gestor Municipal de Puerto Iguazú); GM CDE: (Gestor Municipal de Ciudad Del Este); E: (Enfermeiro); AS: (Assistente Social); AC: (Agente Comunitário).

Seguindo as orientações dos objetivos, as entrevistas foram organizadas para obter informações e dados sobre políticas públicas em saúde visual, os procedimentos utilizados no atendimento dos usuários que residem na tríplice fronteira na particularidade da saúde visual. Após a coleta de dados, sistematizou esses e, em seguida, analisados de forma qualitativa. Os dados também foram quantificados em particularidades para destacar resultados em que aspectos foram apresentados em quadros. A análise dos dados, após a pré-análise da pesquisa de campo, inseriu a interpretação referencial a partir dos conhecimentos teóricos elaborados pela pesquisa bibliográfica. Assim, em seguida, são inicialmente apresentados os cenários dos três municípios da tríplice fronteira (Ciudad Del Este-PY, Foz do Iguaçu-BR e Puerto Iguazú-AR), conforme depoimento dos entrevistados, observações dos locais visitados, bem como dos documentos acessados nos momentos do estudo ora apresentado. Junto com os relatos, aparecem os fundamentos teóricos explicativos do tema deste estudo. 


\section{RESULTADOS E DISCUSSÕES}

Os dados apresentados e discutidos daqui em diante foram organizados por tópicos a partir dos aspectos socioeconômicos e político-culturais de cada país e municípios.

\subsection{SAÚDE VISUAL EM CIUDAD DEL ESTE-PY}

A pesquisa de campo em Ciudad Del Este mostra total falta de estrutura, falta de cuidados pela gestão referente à saúde visual da população. Quem nos recebeu foi o entrevistado GM PY, o qual nos relatou sobre a falta de profissionais no município, do difícil acesso da população para realizar uma consulta com oftalmologista. No hospital público do município não há nenhum profissional de saúde visual. Esse atendimento é prestado pelo setor privado e todos os problemas visuais do município são encaminhados para município vizinho de Porto Franco, no qual há uma fundação especializada em saúde visual que é mantida pela Itaipu Binacional, que realiza exames visuais.

$\mathrm{Na}$ entrevista realizada com a EF CDE, esta relatou que, a população que apresenta problemas visuais, é encaminhada com apoio de recursos monetários para uma consulta. Com o dinheiro em mãos, o usuário da saúde pública decide onde realizar exame oftalmológico (no setor privado do município ou no município do país vizinho). Quando há diagnóstico grave de saúde visual, o usuário é encaminhado diretamente no município vizinho (Porto Franco, que possui convênio com os profissionais da saúde visual da Venezuela, os quais atendem em Porto Franco). Quando há diagnósticos mais graves, os usuários da saúde pública paraguaia são encaminhados diretamente para a Venezuela para o tratamento.

Ainda a $A C$ CDE informa que a população paraguaia procura bastante 0 atendimento em saúde visual no município de Foz do Iguaçu-BR, pelo fácil acesso e valor econômico da consulta.

A entrevista com AC CDE expõe a operacionalidade do atendimento dizendo que, quando ocorrem as visitas às residências da população mais vulnerabilizadas, é realizado um levantamento de dados sobre a situação financeira, estrutura familiar, documentação, matrículas nas escolas públicas. Este levantamento é repassado à Secretaria de bem-estar social de Assunção. Nesse setor, é indicada a equipe especializada que realiza nova visita para continuar o estudo social e repasse de ajuda financeira (uma espécie de transferência de renda brasileira). $O$ valor repassado à família é de $\$ 80,00$ (oitenta dólares mensais). 


\subsection{SAÚDE VISUAL NO MUNICÍPIO DE FOZ DO IGUAÇU- BR}

A pesquisa sobre a estrutura de saúde do município de Foz do Iguaçu, inicialmente, fez a coleta de dados com GM FI (secretário adjunto) municipal. Em Foz do Iguaçu há ampla estrutura para dar atendimento de saúde pública à população. Conforme dados da entrevista de GM FI, esse município integra a 9a Regional da Saúde do Estado do Paraná. A rede pública de saúde de Foz do Iguaçu é composta por uma equipe médica de: médicos clínicos gerais, especialistas em todas as áreas da saúde, biomédicos, dentistas, nutricionista, fisioterapeuta, radiologista, enfermeiros, assistente social, agentes comunitários. No setor de epidemiologia há uma ampla equipe, principalmente para o controle da dengue. Ainda, o entrevistado informou que em Foz do Iguaçu há um hospital municipal que contempla salas cirúrgicas, Unidade de Tratamento Intensivo e leitos para internamento. No município havia três Unidades de Pronto atendimento (UPA, que atende 24 horas com profissionais clínicos gerais, pediatria e radiologia de urgência e internamentos leves).

$\mathrm{Na}$ UPA central ocorrem as consultas com os médicos especialistas, atendimentos das urgências e emergências dos traumas e os centros de radiologia, fisioterapia, laboratório de coletas e exames, apoio aos portadores do HIV e farmácia. Em Foz do Iguaçu havia 28 Postos de Saúde (PS), com atendimento por médicos clínicos gerais, enfermeiros, agentes comunitários e assistentes sociais.

Nessa entrevista ainda, GM Fl informou que até agosto de 2016 havia convênio pelo SUS para atendimento da saúde visual com uma equipe de oftalmologistas de São Paulo. Estes faziam cerca de 100 cirurgias-mês de catarata na população. Este convênio foi rescindido devido a questões políticas e financeiras vividas no município, o que resultou no aumento da fila de espera para atendimentos de saúde visual do município. Na época da pesquisa de campo havia apenas um médico oftalmologista credenciado pelo SUS. Para o atendimento com esse profissional foram estabelecidos critérios, tais como:

Primeiro passo o usuário para por uma consulta no posto de saúde com o médico clinico geral, que faz a avaliação primária e prescreve o encaminhamento para o atendimento com oftalmologista.

Segundo passo o usuário tem que se deslocar até a secretária municipal de saúde munidos de seus documentos, comprovante de endereço e o cartão SUS, aonde o funcionário autorizado analisa os documentos e a solicitação de consulta, e coloca o nome do usuário na lista de espera para o agendamento com o oftalmologista, respeitando as prioridades, urgências, idosos e crianças.

Terceiro passo existe uma agenda para realizar o agendamento das consultas com especialista em saúde visual que é aberta conforme as vagas disponíveis no mês, assim que o usuário e agendado o funcionário liga avisando o dia e horário que fico agendado sua consulta com o oftalmologista. $\mathrm{O}$ atendimento pode demorar até um ano, pois o município só possui um oftalmologista credenciado na rede publica, por falta de recursos financeiros 
no setor público de saúde, foram deixados de realizar alguns pagamentos os médicos conveniados com a prefeitura, no qual os mesmos deixaram de dar atendimento a população na área da saúde visual.

Quando o usuário não tem condições financeiras de comprar seus óculos, ele vai até a assistente social, que faz uma avaliação na ficha do usuário cadastrado no SUS, e depois passa a ele uma autorização para ir até uma ótica do município que é credenciada para fornecer os óculos a população carente.

Os casos de saúde visual que são de extrema urgência são encaminhados para a capital do estado Curitiba para tratamento. (GM FI, 2016)

Nas entrevistas com a AS e EF, referentes ao atendimento aos estrangeiros que vêm à procura de recursos da saúde pública em Foz do Iguaçu (nos dois países há brasileiros residindo e/ou trabalhando), foi relatado que não há como negar o atendimento primário, isto é, as pessoas só têm direito de consultar com o médico clínico geral. Para o atendimento pelos médicos especialistas, é solicitado o cartão SUS, o que impede acesso às especialidades.

Em seguida, os entrevistados AS e AC FI relataram que em Foz do Iguaçu havia oftalmologistas no sistema de saúde privado, bem como havia atendimento por optometristas. Foi manifestado o interesse de a saúde pública inserir nas suas equipes o profissional de optometria, o que favoreceria atenção à população, que nem todas as pessoas podem necessitar do oftalmologista.

\subsection{SAÚDE VISUAL DO MINICÍPIO DE PUERTO IGUAZÚ - AR}

A pesquisa de campo em Puerto Iguazú permitiu observar que a estrutura da saúde municipal é precária e faltam profissionais devido à falta de recursos financeiros e de estruturas físicas. No relato da entrevista com GM PI, na Argentina há restrições de investimentos na saúde pública. A saúde pública de Puerto Iguazú não contemplava profissionais para atender a saúde visual. Em Puerto Iguazú, o atendimento em saúde visual era feito por um médico clínico geral do hospital público. Quando surgem problemas visuais de maior complexidade, os casos são encaminhados para Possadas, município cerca de $300 \mathrm{~km}$ adiante de Puerto Iguazú.

No município vizinho, Eldorado, eram atendidos os casos na saúde visual com menor complexidade. A população espera, por meses, por um atendimento com o profissional de saúde visual. Em Puerto Iguazú só havia um médico oftalmologista atendendo no sistema de saúde privado; quando a pessoa que recorre a esse serviço pagava $\mathrm{P} \$ 800,00$ (oitocentos Pesos), em reais, custa $\mathrm{R} \$ 190,00$ (Cento e noventa reais ) a consulta.

Ainda, segundo os relatos na pesquisa de campo, a intermediação para o atendimento em saúde visual ocorria da seguinte maneira: 
O usuário é levado de ambulância aos municípios de Eldorado e Possadas, e motorista da ambulância do município de Puerto Iguazú, fica encarregado de levar o valor e efetuar o pagamento das despesas do paciente, valor este que a prefeitura disponibiliza em moeda efetiva do país peso, este que varia de cada condições da necessidade da consulta ou exames, "ela não soube explicar o valor correto que cada paciente gasta.

Os moradores argentinos recorriam ao atendimento em Foz do Iguaçu, onde havia oftalmologista na rede privada. Porém, havia cerca de um ano que fora instalada uma Clínica de Optometria bem na fronteira Foz do Iguaçu-Puerto Iguazú, a qual tem o alvará de funcionamento emitido pela Secretaria Municipal de Saúde de Foz do Iguaçu. Nesta clínica são realizados diversos atendimentos, tais como consulta para óculos, lentes de contato e terapias visuais. A clínica é procurada pelos moradores dos países vizinhos, pois o custo desse atendimento é acessível.

\subsection{ANÁLISES E REFLEXÕES}

Os municípios de fronteiras do Brasil têm apresentado inúmeras dificuldades em prover a sua população uma atenção integral de serviços de saúde. As mesmas dificuldades têm sido observadas nos países fronteiriços com o Brasil, gerando uma movimentação das populações ali residentes em fluxos, ora num sentido ora em outro, na busca de melhor oferta de ações e serviços de saúde. Essa mobilidade tem gerado grandes dificuldades para os gestores de saúde dos municípios brasileiros, bem como para as autoridades dos países vizinhos, além de previsíveis problemas diplomáticos e de saúde pública (GADELHA; COSTA, 2007).

No Paraguai, as políticas públicas voltadas para saúde são garantidas pela Constituição Nacional de 1992 que estabelece ao Estado o dever de proteger e promover a saúde como direito fundamental da pessoa e da comunidade. (Constitución de la República de Paraguay, 1992).

Essa posição política converge com a direção brasileira, em que o Estado é o ente garantidor da saúde pública, gratuita, suficiente e de qualidade.

Conforme diz Nogueira e Dal Prá (2006), o sistema coordenado pelo Ministério de Saúde Pública e Bem-Estar Social do Paraguai prevê o fortalecimento institucional das funções de direção, organização, provisão e garantias de acesso, bem como reconhece as atribuições da sociedade na produção social da saúde. Também as atribuições do Conselho Nacional de Saúde no controle de qualidade dos serviços prestados.

No caso brasileiro, o direito à saúde tem garantia exercida pelo Estado Nacional em bases legais pela Constituição Federal de 1988: "Art. $6^{\circ}$ - São direitos sociais a educação, a saúde, o trabalho, o lazer, a segurança, a previdência social, a proteção à maternidade e à infância, assistência aos desamparados na forma desta Constituição" (BRASIL, 1988). 
A política nacional de saúde da Argentina é datada de 1992, amparada no princípio à qualidade e solidário (DAL PRÁ, 2004), porém, apesar de não explicitar CFA de 1992 (Constituição Argentina), a saúde é entendida como um direito de todos os seres humanos. Esse país é composto por 23 províncias, mas é a capital federal que tem a responsabilidade do cuidado e da proteção à saúde, realiza, também, um trabalho descentralizado. A direção política da saúde pela Constituição Argentina de 1992 não contempla a participação e a responsabilidade da sociedade civil por meio das formas de controle social. A participação da população civil fica restrita ao Conselho Federal de Saúde (COFESA).

Do exposto, em linhas gerais sobre direitos e atribuições da saúde pública no três países pesquisados, toma-se por base o exposto por Azevedo (2015), o qual diz que as políticas públicas na área de saúde visual devem integrar a agenda nacional e internacional de maneira descentralizada, que resulte em ações sociais mais dinâmicas pelas experiências concretas verificadas nas regiões fronteiriças.

Deste modo, o desenvolvimento do Sistema Integrado de Saúde nas Fronteiras - SIS-Fronteiras - deveria suprir as dificuldades enfrentadas pelos municípios fronteiriços. O programa SIS-Fronteira foi instituído pela Portaria GM/MS n ${ }^{\circ} 1.120$, de 06 de julho de 2005, alterada pela Portaria GM/MS 1.188, de 05 de junho de 2006, entre os países que fazem parte da tríplice fronteira.

Mesmo assim, há dificuldade da população em ter acesso a esse serviço de saúde visual, tanto pela falta do profissional, como pela falta de programas em saúde visual que possam atender a população. No que tange à saúde visual nos três países, tem uma tendência a ser oferecida, a população é atendida por profissionais do setor privado.

Tal como a saúde era considerada e conduzida pelas pessoas no passado, a saúde visual é um problema de foro individual e a atenção a ela é dada à medida que as pessoas têm ou não renda. A saúde pública, em si, oferece recursos limitados e pontuais, o que diverge, por exemplo, do princípio da integralidade do atendimento aos brasileiros. Então, cada país encontra sua estratégia de minimizar esse problema, mas um ponto é comum: a população com condições de vida não comprometida busca atendimentos em outros municípios, onde o custo da consulta é mais acessível com o profissional de oftalmologia e de Optometria. Assim, recorrer ao país vizinho no município de Foz do Iguaçu é o mais comum. O município de Ciudad Del Este participa do programa SIS-Fronteira, implantado na fronteira com o Brasil, mas atende a população do Paraguai gratuitamente. O mesmo acontece em Puerto Iguazú, há falta de profissionais credenciados na rede pública e o atendimento da população é por meio do encaminhamento para os municípios vizinhos. No mesmo trâmite em Ciudad Del Este-PY, havia dois profissionais de oftalmologia que atendiam na iniciativa privada e o custo da consulta é elevado. Pelo elevado custo, quando a população recorre ao sistema público, é encaminhada aos municípios vizinhos distantes com as despesas pagas pelos recursos da prefeitura municipal.

Se analisar a origem do recurso que custeia essa demanda, pode-se dizer que - Estado arca com as necessidades da população, de outra forma, busca como respostas, que não é com um próprio programa, seus recursos humanos e estruturas. 
Políticas públicas de saúde visual: concepções e práticas na tríplice fronteira entre Argentina, Brasil e Paraguai

Apenas em Foz do Iguaçu a população tem atendimento na saúde pública visual por um oftalmologista credenciado para a rede pública.

Nesse vai e vem entre normas específicas e necessidades das pessoas, a fronteira trinacional (LINI, 2014), pode ser considerada um ponto estratégico, em que as demandas por políticas públicas neste seu contexto devem estar, na medida do possível, adaptadas às particularidades locais. Isto porque nessa região os conceitos de cidadania não são estáticos, são multiformes, concebidos diferentemente sob preceitos legais diferentes. Ainda a configuração social dos três países se assemelha e se diferenciam. Os valores culturais dão destaque aos povos tri fronteiriços que, mesmo com a mobilidade elevada, ainda não fundamentou a política pública especial, nesse caso peculiar.

Por isso, é importante se destacar a diferença dos sistemas de saúde (DAIN, 2004) nos três países, como uma questão que age como um dificultador à integração: o Brasil, por exemplo, é o único país a ter um sistema público universal. Ademais, de acordo com a experiência internacional, a integração do sistema de saúde de uma nação com os demais, cuja qualidade seja diferente, tende a impactar negativamente a qualidade da atenção daquele país. Ainda chama atenção os dizeres de Dain (2004) que, nesse vai e vem fronteiriço, há um impacto sobre a gestão local quando precisa integrar os sistemas, que pode levar à necessidade de substituição conjunta de uma tecnologia por outra mais moderna, posição dos gestores e as análises do custobenefício negativo.

Quadro 1 - Percepção dos gestores municipais em relação aos serviços e os problemas da saúde visual da população

\begin{tabular}{|l|l|l|}
\hline \multicolumn{1}{|c|}{ Municípios } & \multicolumn{1}{c|}{ Percepção } & \multicolumn{1}{c|}{ Problemas } \\
\hline Ciudad Del Este PY & Péssima & $\begin{array}{l}\text { Falta de profissionais, falta de } \\
\text { recursos financeiros }\end{array}$ \\
\hline Foz do Iguaçu-Br & Regular & Falta de recursos financeiros \\
\hline Puerto Iguazú-Ar & Não existe uma percepção & $\begin{array}{l}\text { Falta de profissionais, falta de } \\
\text { recursos financeiros }\end{array}$ \\
\hline
\end{tabular}

Fonte: Dados da pesquisa (2016)

O quadro 1 corrobora as dificuldades e os enfrentamentos quando se analisam os serviços prestados pela saúde pública à população, no recorte da saúde visual. Os entrevistados indicaram as suas dificuldades. Porém, segundo o CONASS, (2005) há dificuldade destes recursos financeiros, humanos e de infraestrutura física. Para esse caso agravado pela super utilização da saúde pública que, sequer, conseguiu focar na saúde visual, para esses municípios das regiões fronteiriças há indicativo do Ministério da Saúde brasileiro da formalização da integração entre sistemas de saúde de fronteiras, a partir do reconhecimento das dificuldades historicamente vivenciadas por gestores e usuários nestas localidades.

O autor Lini (2014) reitera, assim, a importância da integração na formulação e implementação das políticas públicas nos diversos níveis governamentais para o atendimento adequado das demandas específicas de espaços geográficos 
diferenciados. Ainda que cada município possua regramentos próprios, o diálogo e a identificação das fragilidades comuns são ferramentas indispensáveis para a escolha adequada ao atendimento da população fronteiriça.

Quadro 2 - Programas ou ações desenvolvidas sobre a saúde visual nos município estudados

\begin{tabular}{|l|l|l|}
\hline \multicolumn{1}{|c|}{ Municípios } & \multicolumn{1}{|c|}{ Programas/ ações } & \multicolumn{1}{c|}{ Objetivos } \\
\hline $\begin{array}{l}\text { Ciudad Del Este- } \\
\text { PY }\end{array}$ & $\begin{array}{l}\text { Há convênios com APP } \\
\text { (Associação Público Privado) e a } \\
\text { Fundação Visão }\end{array}$ & $\begin{array}{l}\text { Ajudar a população para ter atendimento } \\
\text { na saúde visual }\end{array}$ \\
\hline Foz do Iguaçu-BR & $\begin{array}{l}\text { No momento não há ações e } \\
\text { projetos em saúde visual no } \\
\text { município }\end{array}$ & $\begin{array}{l}\text { Não tem um objetivo, pois não temos } \\
\text { projetos }\end{array}$ \\
\hline Puerto Iguazú AR & $\begin{array}{l}\text { Não há ações, pois não há } \\
\text { profissional responsável pela } \\
\text { saúde visual na saúde pública do } \\
\text { município. }\end{array}$ & $\begin{array}{l}\text { Não há projetos, mas se houvesse seria } \\
\text { trazer especialistas na saúde visual para } \\
\text { o beneficio da população, para não terem } \\
\text { que se deslocar 300 km para realizar um } \\
\text { tratamento ou uma cirurgia e não } \\
\text { precisar buscar recurso no país vizinho } \\
\text { Brasil. }\end{array}$ \\
\hline
\end{tabular}

Fonte: Dados da pesquisa (2016)

As respostas confirmam a fragilidade da saúde visual como uma preocupação de segunda ordem. Assim, afirma Temporini (1991), que os programas de saúde pública para a oftalmologia devem priorizar ações relacionadas à prevenção de estados conducentes à cegueira e à incapacidade visual, à promoção de saúde visual e organização de assistência oftalmológica, e à reabilitação dos deficientes visuais.

Essa demanda populacional sequer faz parte do Plano Municipal de Saúde de 2014 a 2017 do município de Foz do Iguaçu. Não foram localizados documentos semelhantes ao PMS brasileiro, nos municípios de Ciudad Del Este e Puerto Iguazú. Porém, nos relatos dos entrevistados mencionaram que tal documento poderia estar apenas na mão do gestor principal. Bem, isso pode ser denominado de centralização do poder ou de manipulação das intervenções. Ainda, é passível de questionamento sobre as necessidades de conhecimentos dos gestores municipais.

Quadro 3 - Os profissionais que atuam na saúde pública no atendimento em saúde Visual dos municípios.

\begin{tabular}{|l|c|}
\hline \multicolumn{1}{|c|}{ Municípios } & Profissionais \\
\hline Ciudad Del Este-PY & 0 \\
\hline Foz do Iguaçu-BR & 01 \\
\hline Puerto Iguazú-AR & 0 \\
\hline
\end{tabular}

Fonte: Dados da pesquisa (2016) 
Políticas públicas de saúde visual: concepções e práticas na tríplice fronteira entre Argentina, Brasil e Paraguai

Pelas respostas acima, é possível ver que, para atender cerca de 729.227 milhões de habitantes nesses municípios, há déficit de profissionais no setor público. Assim, a demanda pela atenção à saúde visual, ou recorre à iniciativa privada ou os atendimentos primários são prestados por um médico clínico geral, que só depois a população é encaminhada a um oftalmologista, conforme a necessidade de cada usuário da rede pública de Ciudad Del Este, Foz do Iguaçu e Puerto Iguazú.

Consideram Murthy e Raman (2009) que os cuidados primários da saúde da visão não podem ser considerados uma atividade individual, mas devem ser integrados num sistema de cuidados primários de saúde já existentes. Como menos de $1 \%$ da população está em risco real de cegueira, parece difícil sustentar um programa completo de atendimento a essa situação que envolve problemas da visão. Contudo, a motilidade (movimentos) ocular é muito maior, o que pode justificar uma redistribuição de mais recursos para os cuidados primários da saúde da visão. Porque a saúde da visão como cuidado primário é relativamente cara e tem melhor retorno que os cuidados primários de saúde em geral; pode ser mais facilmente criado um centro de cuidados primários da visão que um centro de cuidados primários da saúde. Trata-se de outra abordagem sobre a criação de um centro no qual múltiplas atividades de saúde sejam executadas em coordenação da saúde visual.

Quadro 4 - Convênio entre as Secretarias Municipais de Saúde dos municípios da tríplice fronteira e serviços que os moradores necessitam buscar em outros municípios

\begin{tabular}{|l|l|l|}
\hline \multicolumn{1}{|c|}{ Municípios } & \multicolumn{1}{|c|}{ Parceria } & \multicolumn{1}{c|}{ Serviços } \\
\hline Ciudad Del Este & Não há convênio com outros país & $\begin{array}{l}\text { Oftalmologista/ Optometrista na } \\
\text { rede privada }\end{array}$ \\
\hline Foz do Iguaçu & Não há convênio com outros país & Nenhum serviço \\
\hline Puerto Iguazú & Não há convênio com outros país & $\begin{array}{l}\text { Oftalmologista/ Optometrista na } \\
\text { rede privada }\end{array}$ \\
\hline
\end{tabular}

Fonte: Dados da pesquisa (2016)

Pelos dados acima (Quadro 4) é possível afirmar a defasagem de estudos para dimensionar a demanda reprimida a qual exerce pressão sobre como devem se organizar os sistemas municipais de saúde. O SUS brasileiro e os similares do PY e AR devem atender as necessidades da população, conforme seus compromissos legais.

Quadro 5 - Sobre a atuação do profissional de Optometria na saúde pública.

\begin{tabular}{|l|c|c|c|c|c|c|c|c|}
\hline \multicolumn{1}{|c|}{ MUNICÍPIO } & \multicolumn{4}{c|}{ ATUAÇÃO } & \multicolumn{4}{c|}{ DIFERENÇA ENTRE O } \\
& OFTALMOLOGISTA/OPTOMETRISTA \\
\hline & RGM & RE & RAS & RAC & RGM & RE & RAS & RAC \\
\hline Ciudad Del Este & NÃO & NÃO & NÃO & NÃO & SIM & SIM & NÃO & SIM \\
\hline Foz do Iguaçu & NÃO & NÃO & NÃO & NÃO & SIM & NÃO & NÃO & NÃO \\
\hline Puerto Iguazú & NÃO & NÃO & NÃO & NÃO & SIM & NÃO & NÃO & SIM \\
\hline
\end{tabular}

Fonte: Dados da pesquisa (2016)

Saúde Meio Ambient. v. 6, n. 2, p. 108-123, jul./dez. 2017 
Mesmo que as respostas sobre a atuação do optomestrista tenham mostrado conhecimento sobre esse profissional, os entrevistados relataram que este seria um profissional importante para a saúde pública de cada município, pois iria diminuir a fila de espera. Seria uma forma de enfrentamento da demanda reprimida.

Esta é afirmação dos entrevistados, os quais disseram que: RGM PI: "Solucionaria os problemas visuais, aliviando a fila de espera para consultas no município vizinho." RGM CDE: "Melhoraria o acesso à saúde visual do município, pois não há profissionais na rede pública, somente na rede privada." RGM FI: "Diminuiria a fila de espera, que hoje é grande no município, agilizaria para os usuários que necessitam de óculos, assim, não sobrecarregaria o profissional de oftalmologia."

Sabe-se que nesse campo de atuação profissional a atenção oftálmica especializada pode ser prestada pelos: oftalmologistas, optometristas, enfermeiros especializados em oftalmologia ópticos, e os profissionais de atenção primários em nível médio. $O$ trabalho em equipe $e$ as atividades com profissionais de interdisciplinares são áreas chaves em que se deve investir, a fim de melhorar a eficácia e eficiência dos serviços de atenção à saúde e aperfeiçoar a contribuição de cada membro da equipe para melhorar o atendimento em saúde visual na saúde pública (ORGANIZAÇÃO MUNDIAL DA SAÚDE, 2008).

Quadro 6 - Resumo geral das dificuldade na saúde pública dos municípios a respeito da saúde visual

\begin{tabular}{|l|c|c|c|}
\hline \multicolumn{1}{|c|}{ Municípios } & $\begin{array}{c}\text { Tempo de espera } \\
\text { por uma consulta }\end{array}$ & $\begin{array}{c}\text { Número de usuários } \\
\text { mensais }\end{array}$ & $\begin{array}{c}\text { Falta do profissional } \\
\text { na rede publica }\end{array}$ \\
\hline Cuidad Del Este & Mais de 90 dias & Mais de 100 pessoas & Não possui \\
\hline Foz do Iguaçu & 60 a 90 dias & 60 pessoas & 01 \\
\hline Puerto Iguazú & 60 dias & Mais de 30 pessoas & Não possui \\
\hline
\end{tabular}

Fonte: Dados da pesquisa (2016)

As respostas do quadro 6 corroboram com as dificuldades das populações na tríplice fronteira, quando se trata de atendimento em saúde visual, por falta de profissionais credenciados à rede pública dos municípios estudados.

Por isso, com respaldo em Kamikawa e Motta (2014, p. 363) o direito à saúde está diretamente ligado ao direito à vida e que, dada a sua essencialidade, também é classificado como um direito da personalidade. Pois, é perfeitamente conclusivo que, se o indivíduo não puder gozar de saúde, outros direitos não lhe despertarão interesse e nem poderão, sequer, serem exercidos.

Dessa maneira, a discussão sob a temática da saúde visual na fronteira deve ser um ponto importante para as instituições, pois o processo de construção da identidade transfronteiriça e a capacitação de agentes locais de saúde são a base para políticas eficientes, políticas que considerem a cooperação como questão primordial. 


\section{CONCLUSÃO}

O debate sobre a situação da saúde visual nas fronteiras acontece há muito tempo, porém, seja pela falta de ordenação das iniciativas públicas ou pela formulação de estratégias de caráter a situação permaneceu praticamente inalterada. Ao estudálas, há que se ter em mente as concepções em políticas públicas em saúde visual, especificidades que compõem essa temática, além das relações estabelecidas entre os indivíduos que dela fazem parte.

As políticas públicas existentes relacionadas à fronteira têm a missão de garantir o atendimento à saúde para a população fronteiriça migrante, devendo auxiliar os gestores municipais de saúde na elaboração de estratégias, melhorando os sistemas de saúde locais, porém, não é o que acontece. Notou-se, neste estudo, a falta de programas e projetos, falta de profissionais, de estruturas físicas para o atendimento a saúde visual da tríplice fronteira. Ao mesmo tempo em que alguns programas garantem o atendimento, legislações dificultam a inserção do usuário, como a obrigatoriedade do cartão SUS, por exemplo.

A impossibilidade de estender o estudo nos municípios argentinos e paraguaios constituiu uma limitação importante durante o trabalho, visto a dificuldade de se buscar dados atualizados das condições de atendimento e dos planos municipais de saúde. Verificou-se, durante o trabalho, que os sistemas de saúde dos três países estudados são extremamente heterogêneos quanto à forma de organização, gestão e financiamento. Essas diferenças voltadas para área da saúde visual desses países apresentam-se como a principal questão a ser repensada na perspectiva de uma real melhora do sistema de saúde em geral.

O fluxo de estrangeiros que buscam melhor oferta de ações e serviços de saúde visual no município de Foz do Iguaçu-BR vem criando insatisfação aos gestores públicos que se deparam, diariamente, com dificuldades para administrar suas secretarias. É visível a insatisfação quanto ao atendimento à população fronteiriça, pela falta de incentivo financeiro para melhoria da qualidade do atendimento na saúde visual e a falta constante de profissionais em relação à qualidade de atendimento na saúde visual.

As políticas e as ações da saúde pública na fronteira traduzem tensões e dilemas relacionados às reivindicações do Estado, mas também aponta para um complexo movimento de ampliação de direitos e práticas de integração fronteiriça.

Os direitos universais à vida e à saúde entram em colisão com os limites orçamentários dos setores de saúde e a defesa do atendimento somente para os residentes daquele município ou de outra cidade brasileira.

Por fim, torna-se imprescindível desenvolver políticas públicas em saúde visual que permitam superar o paradigma de fronteira como algo problemático, fortalecendo o seu desenvolvimento, valorizando e fortalecendo suas características. 


\section{REFERÊNCIAS}

AZEVEDO, Suelen Terre. 0 tranfronteiriço e o atendimento público de saúde na fronteira Brasil/Paraguai, 2015 Mestranda em Geografia da Universidade Estadual do Oeste do Paraná (Unioeste).

BRASIL. Conselho Nacional de Secretários de Saúde. Gestão e Financiamento do Sistema Único de Saúde/Conselho Nacional de Secretários de Saúde. - Brasília: CONASS, 2008. 150 p. (CONASS Documenta; 14) Acesso em: 30 set. 2016

BRASIL. Ministério da Saúde. Secretaria de Atenção à Saúde. Departamento de Atenção Básica. Política Nacional de Atenção Básica/Ministério da Saúde, Secretaria de Atenção à Saúde, Departamento de Atenção Básica. Brasília: Ministério da Saúde. 2006. Acesso em: 07 maio 2016.

DAIN, S., Subsídios para a Formulação de um Sistema de Integração dos Modelos de Prestação de Serviços de Saúde no MERCOSUL e suas Regiões de Fronteira: harmonização e transfronteirização dos sistemas de saúde. Brasília, Mimeo. mar., 2004

DAL PRA, Keli Regina. Reformas do Setor Saúde nos países do Mercosul: As reformas na Argentina. In: SIMIONATTO, Ivete; NOGUEIRA, Vera Maria Ribeiro (org.). Dilemas do Mercosul: reforma do estado, direito à saúde e perspectivas da agenda social. Universidade Federal de Santa Catarina. Florianópolis: Lagoa Editora, 2004. p. 95-103.

GADELHA C. A. G, Costa L. Integração de fronteiras: a saúde no contexto de uma política nacional de desenvolvimento. Cad. Saúde Pública, Rio de Janeiro, 23 Sup2: S214226, 2007.

LINI, Priscila. Políticas públicas na fronteira trinacional: o desafio ao pleno exercício da cidadania. Revista Brasileira de Políticas Públicas, Brasília, v. 4, n. 1, 2014 p. 173-184. http://.uniceub.br/index.php/RBPP/article/view/2813/pdf_1. Acesso em: 18 jun. 2016

GIOVANELLA, Ligia et al. Saúde nas fronteiras: acesso e demandas de estrangeiros e brasileiros não residentes ao SUS nas cidades de fronteira com países do MERCOSUL na perspectiva dos secretários municipais de saúde. Cad. Saúde Pública, Rio de Janeiro 2007, v. 23, suppl. 2, p. S251-S266.

KAMIKAWA, Gisele Keiko; MOTTA, Ivan Dias da. Direito à saúde e estudo da política pública do Programa "Mais Médicos". Revista Jurídica Cesumar:

Mestrado, Maringá, v. 14, n. 2, p. 341-367, jul./dez. 2014.

NOGUEIRA V.; DAL PRÀ Karla. R. Mercosul: expressões das desigualdades em saúde na linha da fronteira. Ser Social, Brasília, n. 18, p. 159-188, jan./jun. 2006. Disponivel:books.scielo.org/id/wcdsj/pdf/organizacao-9788575413982-00.pdf. Acesso em: 20 jul. 2016 
PADILHA, Miguel Angelo. $O$ direito de ver. Disponível em:

<http://www.sboportal.org.br/sbo/scripts/ap/destaques/3.asp>Acesso em: 28 abr.

2016

OPS/OMS. Organização Pan-Americana da Saúde. A saúde e as relações internacionais: seu vinculo com a gestão do desenvolvimento nacional da saúde Resolução CE142.R14. 142 Sessão do Comitê Executivo da OPS/OMS.

Washington, 2008. Acesso em: 28/09/2016

RAMOS, Murilo César. Comunicação, direitos sociais e políticas públicas. In MARQUES DEMELO, J.; SATHLER, L. Direitos à Comunicação na Sociedade da Informação. São Bernardo do Campo, SP: Unesp, 2005.

MURTHY G., Raman, U. Perspective on primary eye care. Community Eye Health Journal, v. 22, n. 69, p.10, 2009. Disponível em: <http://www.cehjournal.org/ wpcontent/uploads/download/ceh_22_69_010.pdf>. Acesso em: 01 out. 2016

TEMPORINI, Edméa Rita; KARA-JOSE, Newton. A perda da visão: estratégias de prevenção. Arq. Bras. Oftalmol., São Paulo, v. 67, n. 4, p. 597-601, Aug. 2004.

PARAGUAY. Constitución de la República de Paraguay, 1992. Disponível en <http://www.unhcr.org/ refworld/docid/3dbe93f49.html>. Acesso em 01 out. 2016

OPS/OMS. Salud en las américas, 2007. v. 2. PAíS Paraguay. Alum, J.N.M; Bejarano, M.S.C. Sistema de Salud de Paraguay. Rev. Salud Pública Parag. v.1, n, p. 13-25, 2011.

Artigo recebido em: 11/08/2017

Artigo aprovado em: 11/12/2017

Artigo publicado em: 20/12/2017 